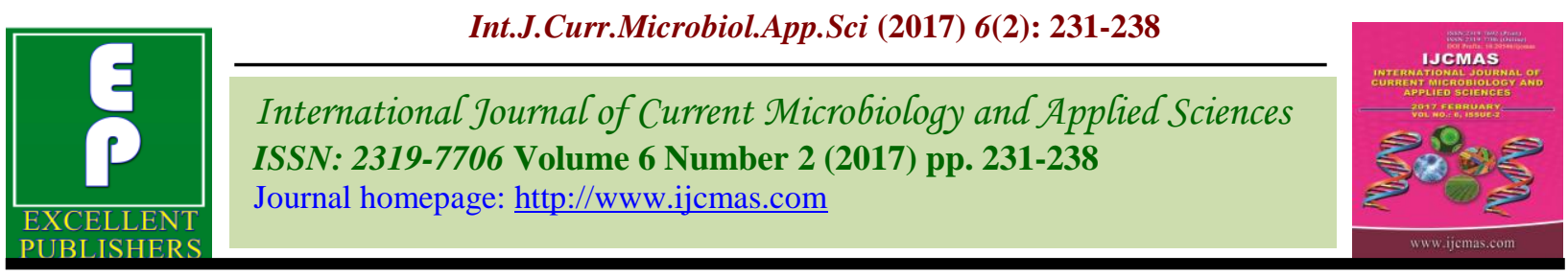

Original Research Article

http://dx.doi.org/10.20546/ijcmas.2017.602.030

\title{
Determination of Fosetyl Aluminium Fungicide Residues in Garlic using HPLC Method
}

\author{
Nageswara Rao Tentu ${ }^{1 *}$, Botsa Parvatamma ${ }^{2}$, Karri Apparao, \\ Prathipati Revathi ${ }^{1}$ and Y. Prashanthi ${ }^{3}$
}

${ }^{1}$ Department of Chemistry, Krishna University, Machilipatnam, AP, India

${ }^{2}$ Department of organic Chemistry, Gayathri P.G Courses, Gotlam, Vizianagaram, AP, India

${ }^{3}$ Department of Chemistry, Mahatma Gandhi University, Telangana State, India

*Corresponding author

\begin{tabular}{|c|c|}
\hline & A B S T R A C T \\
\hline $\begin{array}{l}\text { Ke y w o r d s } \\
\text { HPLC, Fosetyl } \\
\text { Aluminium, } \\
\text { Garlic, } \\
\text { LOD and } \\
\text { LOQ. }\end{array}$ & $\begin{array}{l}\text { A simple and inexpensive method was developed using liquid - liquid } \\
\text { extraction, together with high performance chromatographic method for } \\
\text { determination of fosetyl aluminium residues in garlic. The evaluated } \\
\text { parameters include the extracts by distilled water and methanol solvents. } \\
\text { The method was validated using garlic samples spiked with fosetyl } \\
\text { aluminium at different fortification levels }(0.030\end{array}$ \\
\hline Article Info & recoveries (using each concentration three replicates) ranged $88-97 \%$, with \\
\hline $\begin{array}{l}\text { Accepted: } \\
\text { 12 January } 2017 \\
\text { Available Online: } \\
10 \text { February } 2017\end{array}$ & $\begin{array}{l}\text { relative standard deviations less than } 2 \% \text {, calibration solutions } \\
\text { concentration in the range } 0.03-2.0 \mu \mathrm{g} / \mathrm{mL} \text { and limit of detection (LOD) } \\
\text { and limit of quantification (LOQ) were } 0.01 \mu \mathrm{g} / \mathrm{g} \text { and } 0.03 \mu \mathrm{g} / \mathrm{g} \text { respectively. } \\
\text { Finally the garlic residue samples were analyzed by HPLC. }\end{array}$ \\
\hline
\end{tabular}

\section{Introduction}

Fosetyl aluminum is a fungicide used worldwide to control diseases caused by members of the Peronosporales, especially root and crown rots caused by various Phytophtora species and foliar diseases caused by some downy mildews (Barrett S.R et al., 2003). Although the mode of action of fosetyl-Al still remains controversial, it is probable that its breakdown product, the phosphonate anion, produces a direct antifungal effect on disease control, inhibiting growth and sporulation of a pathogen such as Phytophthora (Giordano et al., 1995).
Fosetyl-Al is available in commercial formulations as wet powders (WP) and wet dispersible granules (WG). It is commonly found in combination with other pesticides such as mancozeb, cymoxanil, and folpet. Chemically, fosetyl-Al is the aluminium salt of the phosphonic acid monoethyl ester. According to IUPAC rules, the term "phosphonate" denotes the ionic form of the phosphonic acid and, for that reason; it is also used for denoting its salts and esters (Hernández et al., 2003). Fosetyl- aluminum, is a molecule which has a low molecular 
mass, ionic structure, and lacks UV absorption or fluorescence (Hooijschuur et al., 2001). For these reasons, it is rather difficult to determine fosetyl- aluminum by conventional (reversed-phase) liquid chromatography, hence it has traditionally been separated by high performance ion chromatography (Moller et al., 2003), gas chromatography after derivatisation, (Ouimette et al., 1989) or micro column liquid chromatography (Pelegri et al., 1993) and measured by using conductivity detection or flame photometric detection in environmental samples and food.

\section{Materials and Methods}

\section{Standards, reagents and samples}

\section{Instrument :}

The analytical standard of fosetyl aluminum (98.8\%) was obtained from Sigma Aldrich. HPLC grade methanol and water was purchased from rankem and garlic was purchased from local market.

\section{Standard stock solutions}

Mobile phase B :

The fosetyl aluminum stock solutions was individually prepared in acetonitrile at a concentration level $500 \mu \mathrm{g} / \mathrm{g}$ and stored in a freezer at $-18^{\circ} \mathrm{C}$.

The stock standard solutions were used for up to 3 months. Suitable concentrations of working standards were prepared from the stock solutions by dilution using acetonitrile, immediately prior to sample preparation.

\section{Sample preparation}

Representative 100.0 gram portions of garlic fortified with $0.1 \mathrm{~mL}$ of working standard stock solution. The sample was allowed to stand at room temperature for one hour, before it was kept at refrigerator condition, until analysis.

\section{Extraction procedure of garlic}

The homogenized sample (10 g) was taken in a centrifuge tube and to it $30 \mathrm{~mL}$ water was added. The mixture was vortexed for $30 \mathrm{~s}$ and then placed in a microwave for $1 \mathrm{~min}$. The sample was allowed to cool to room temperature and then centrifuged for 5 minutes at $5000 \mathrm{rpm} .2 \mathrm{~mL}$ of this supernatant was transferred into an Eppendorf tube and centrifuged at $10000 \mathrm{rpm}$ for $5 \mathrm{~min}$. The clear supernatant was filtered through $0.2 \mu \mathrm{m}$ membrane filter and subsequently injected to HPLC for estimation of the residues

\section{Instrumentation}

\section{HPLC-PDA Separation parameters}

Shimadzu 2010 HPLC system connected with LC Solution software system.

Detector : Photodiode Array (PDA)

Column used : PhenomenexLuna-C18 (150 $\mathrm{mm} \times 4.6 \mathrm{~mm} \times 5 \mu)$

Mobile Phase A: $50 \%$ of $5 \mathrm{~mm}$ ammonium formate in Methanol

Mobile Phase B $50 \%$ of $5 \mathrm{~mm}$ ammonium formate in Milli Q Water

Flow $\quad: 0.8 \mathrm{~mL}$ per minute

Injection volume $: 20 \mu \mathrm{L}$

Oven Temperature: $30^{\circ} \mathrm{C}$

Retention time in minutes

(Approximately) : 4.5 minutes

\section{Method validation}

Method validation ensures analysis credibility. In this study, the parameters accuracy, precision, linearity and limits of detection (LOD) and quantification (LOQ) were considered (Tentu Nageswara Rao et al., 2015; Nageswara Rao et al., 2012). The accuracy of the method was determined by recovery tests, using samples spiked at concentration levels of 0.01 and $0.1 \mu \mathrm{g} / \mathrm{g}$. Linearity was determined by different known 
concentrations $(0.03,0.1,0.3,0.6,1.0$ and $2.0 \mu \mathrm{g} / \mathrm{mL}$ ) were prepared by diluting the stock solution. The limit of detection (LOD $\mu \mathrm{g} / \mathrm{g}$ ) was determined as the lowest concentration giving a response of 3 times the baseline noise defined from the analysis of control (untreated) sample. The limit of quantification (LOQ $\mu \mathrm{g} / \mathrm{g}$ ) was determined as the lowest concentration of a given fungicide giving a response of 10 times the baseline noise.

\section{Results and Discussion}

\section{Specificity}

Aliquots of fosetyl aluminum, control sample solution, extracted solvents and mobile phase solvents were assayed to check the specificity. There were no matrix peaks in the chromatograms to interfere with the analysis of residues shown in (Figure 1 and 2). Furthermore, the retention time of fosetyl aluminum was $4.5 \mathrm{~min}$ (Approximately).

\section{Linearity}

$50.61 \mathrm{mg}$ of fosetyl aluminum reference standard was taken into $50 \mathrm{~mL}$ volumetric flask and dissolved in HPLC water, sonicated and made upto the mark with the same solvent. The concentration of the stock solution was $1000 \mu \mathrm{g} / \mathrm{mL}$. From this stock solution prepared by different known concentrations of standard solutions $(0.03$, $0.1, \quad 0.3,0.6, \quad 1.0$ and $2.0 \mu \mathrm{g} / \mathrm{mL}$ ) were prepared into different $10 \mathrm{~mL}$ volumetric flasks and made upto the mark with acetone. The serial dilution details were presented in table 1 . These standard solutions were directly injected into a HPLC. A calibration curve has been plotted of concentration of the standards injected versus area observed and the linearity of method was evaluated by analyzing six solutions. The calibration details were given in table 2. The peak areas obtained from different concentrations of standards were used to calculate linear regression equation. This was $\mathrm{Y}=7497.65 \mathrm{X}+3.58$ with correlation coefficient of 1.0000 respectively. A calibration curve showed in (Figure 3).

\section{Accuracy and precision}

Recovery studies were carried out at $0.03,0.1$ and $0.3 \mu \mathrm{g} / \mathrm{g}$ fortification levels for fosetyl aluminum in garlic. The recovery data and relative standard deviation values obtained by this method are summarized in table 2 .

\section{Detection and quantification limits}

The limit of quantification was determined to be $0.03 \mu \mathrm{g} / \mathrm{g}$. The quantitation limit was defined as the lowest fortification level evaluated at which acceptable average recoveries $(88-97 \%, \quad \mathrm{RSD}<2 \%) \quad$ were achieved. This quantitation limit also reflects the fortification level at which an analyte peak is consistently generated at approximately 10 times the baseline noise in the chromatogram (SANCO Guidelines, 2009). The limit of detection was determined to be $0.03 \mu \mathrm{g} / \mathrm{g}$ at a level of approximately three times the back ground of control injection around the retention time of the peak of interest.

\section{Storage stability}

A storage stability study was conducted at refrigerator condition $\left(5 \pm 3^{\circ} \mathrm{C}\right)$ and Ambient temperature $\left(25 \pm 5^{\circ} \mathrm{C}\right)$ of $0.6 \mu \mathrm{g} / \mathrm{g}$ level fortified fruit samples were stored for a period of 30 days at this temperature and analysed for the content of fosetyl aluminum before storing and at the end of storage period. The percentage dissipation observed for the above storage period was only less than $3 \%$ for fosetyl aluminum showing no significant loss of residues on storage. The results are presented in table 3 and 4. 
Table.1 Serial dilutions of linearity standard solutions

\begin{tabular}{|c|c|c|c|}
\hline $\begin{array}{c}\text { Stock solution } \\
\text { concentration } \\
(\boldsymbol{\mu g} / \mathbf{m L})\end{array}$ & $\begin{array}{c}\text { Volume taken } \\
\text { from stock } \\
\text { solution }(\mathbf{m L})\end{array}$ & $\begin{array}{c}\text { Final } \\
\text { make up } \\
\text { volume } \\
(\mathbf{m L})\end{array}$ & $\begin{array}{c}\text { Obtained } \\
\text { concentration } \\
(\boldsymbol{\mu g} / \mathbf{m L} \mathbf{L})\end{array}$ \\
\hline 1000 & 0.100 & 10 & 10.0 \\
\hline 10 & 2.000 & 10 & 2.0 \\
\hline 10 & 1.00 & 10 & 1.0 \\
\hline 10 & 0.6 & 10 & 0.6 \\
\hline 10 & 0.3 & 10 & 0.3 \\
\hline 10 & 0.1 & 10 & 0.1 \\
\hline 1.0 & 0.3 & 10 & 0.03 \\
\hline
\end{tabular}

Table.2 Recoveries of the fosetyl aluminum from fortified garlic control sample $(n=3)$

\begin{tabular}{|c|c|c|}
\hline \multirow{2}{*}{$\begin{array}{c}\text { Fortified } \\
\text { Concentration } \\
(\mathbf{m g} / \mathbf{k g}) \\
\end{array}$} & \multirow{2}{*}{ Replication } & \multirow{2}{*}{$\begin{array}{c}\text { Recovery (\%) } \\
\text { Garlic } \\
\end{array}$} \\
\hline & & \\
\hline \multirow{4}{*}{0.03} & R1 & 87.23 \\
\hline & $\mathbf{R 2}$ & 88.11 \\
\hline & R3 & 88.74 \\
\hline & Mean \pm S.d. & $88.03 \pm 0.76$ \\
\hline \multirow{4}{*}{0.1} & R1 & 92.54 \\
\hline & $\mathbf{R 2}$ & 91.84 \\
\hline & R3 & 93.65 \\
\hline & Mean \pm S.d. & $92.68 \pm 0.91$ \\
\hline \multirow{4}{*}{0.3} & R1 & 96.86 \\
\hline & $\mathbf{R 2}$ & 97.64 \\
\hline & $\mathbf{R 3}$ & 96.57 \\
\hline & Mean \pm S.d. & $97.02 \pm 0.55$ \\
\hline
\end{tabular}

These numbers were calculated from four (3) replicate analyses of given sample (fosetyl aluminum) made by a single analyst on one day. The repeatability of method satisfactory (RSDs $<2 \%)$. 
Table. 3 Storage stability details at refrigerator condition $\left(5 \pm 3^{\circ} \mathrm{C}\right)$

\begin{tabular}{|c|c|c|}
\hline $\begin{array}{l}\text { Fortification } \\
\text { Concentration } \\
\text { in } \mu \mathrm{g} / \mathrm{g}\end{array}$ & $\begin{array}{l}\text { Storage } \\
\text { Period in } \\
\text { Days }\end{array}$ & Recovery in \% \\
\hline \multirow{18}{*}{0.3} & \multirow{6}{*}{0} & 98 \\
\hline & & 96 \\
\hline & & 95 \\
\hline & & 97 \\
\hline & & 98 \\
\hline & & 97 \\
\hline & \multirow{3}{*}{$\begin{array}{c}\text { Average } \\
\text { STDEV } \\
\text { RSD in \% }\end{array}$} & 96.83 \\
\hline & & 1.17 \\
\hline & & 1.21 \\
\hline & \multirow{6}{*}{30} & 95 \\
\hline & & 96 \\
\hline & & 94 \\
\hline & & 95 \\
\hline & & 93 \\
\hline & & 94 \\
\hline & \multirow{3}{*}{$\begin{array}{c}\text { Average } \\
\text { STDEV } \\
\text { RSD in \% }\end{array}$} & 94.50 \\
\hline & & 1.05 \\
\hline & & 1.11 \\
\hline
\end{tabular}

Table.4 Storage stability details at ambient temperature $\left(25 \pm 2^{\circ} \mathrm{C}\right)$

\begin{tabular}{|c|c|c|}
\hline $\begin{array}{c}\text { Fortification } \\
\text { Concentration } \\
\text { in } \mu \mathrm{g} / \mathrm{g}\end{array}$ & $\begin{array}{c}\text { Storage } \\
\text { Period in } \\
\text { Days }\end{array}$ & Recovery in \% \\
\hline \multirow{18}{*}{ (ingos } & \multirow{6}{*}{ 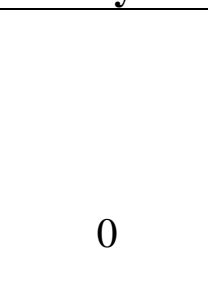 } & 96 \\
\hline & & 95 \\
\hline & & 93 \\
\hline & & 95 \\
\hline & & 95 \\
\hline & & 94 \\
\hline & \multirow{3}{*}{$\begin{array}{c}\text { Average } \\
\text { STDEV } \\
\text { RSD in \% }\end{array}$} & 94.67 \\
\hline & & 1.03 \\
\hline & & 1.09 \\
\hline & \multirow{6}{*}{30} & 92 \\
\hline & & 93 \\
\hline & & 90 \\
\hline & & 91 \\
\hline & & 93 \\
\hline & & 92 \\
\hline & \multirow{3}{*}{$\begin{array}{c}\text { Average } \\
\text { STDEV } \\
\text { RSD in \% }\end{array}$} & 91.83 \\
\hline & & 1.17 \\
\hline & & 1.27 \\
\hline
\end{tabular}


Fig.1 Representative chromatogram at garlic control

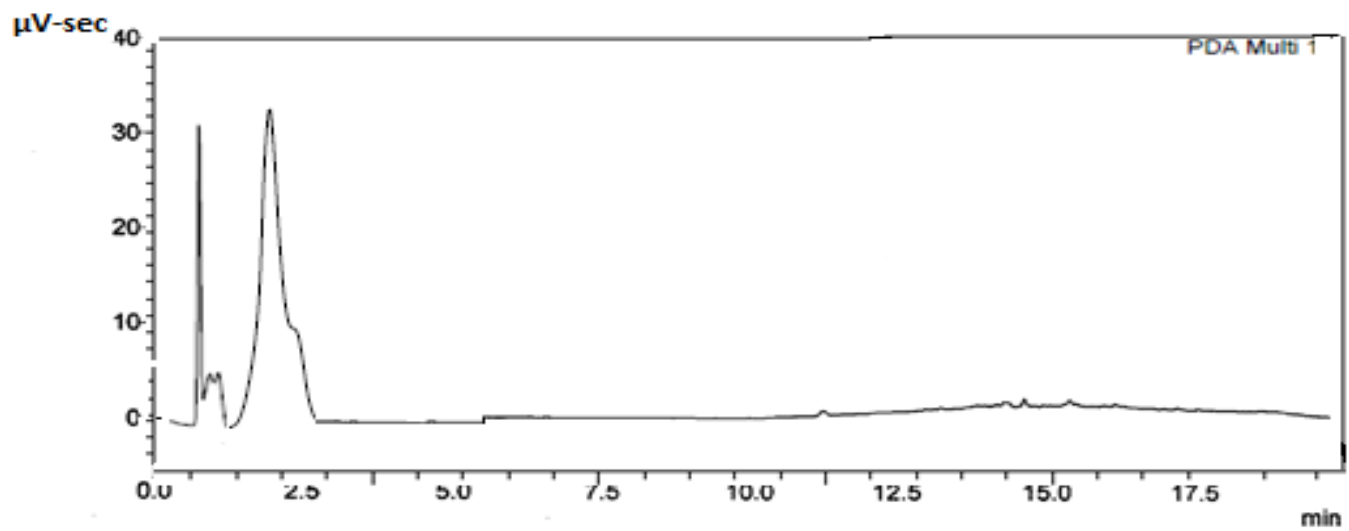

Fig.2 Representative chromatogram at fortification level of $0.01 \mu \mathrm{g} / \mathrm{g}$

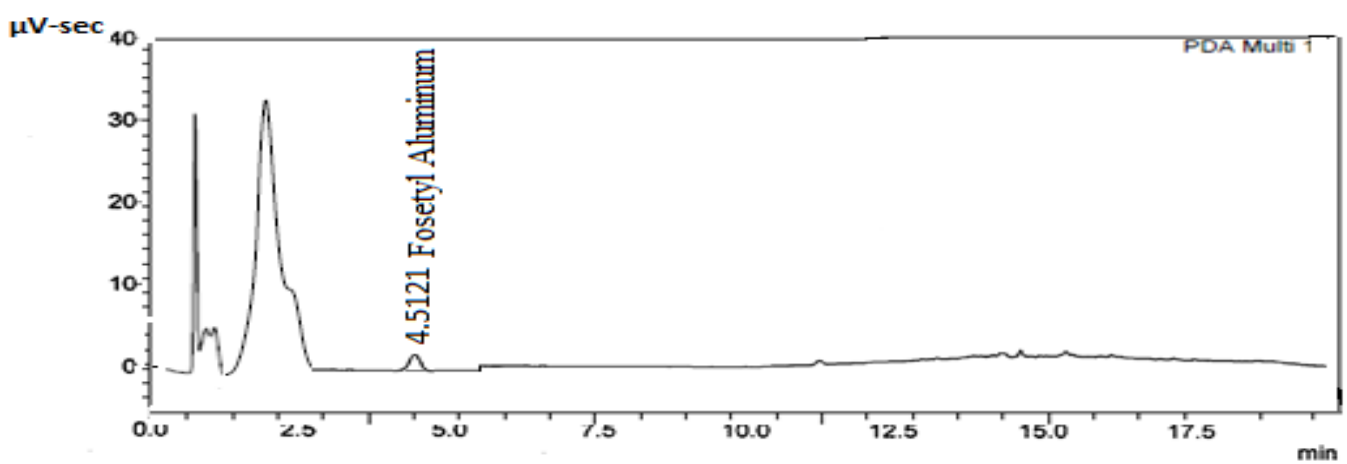

Fig.3 Representative calibration curve of fosetyl aluminum

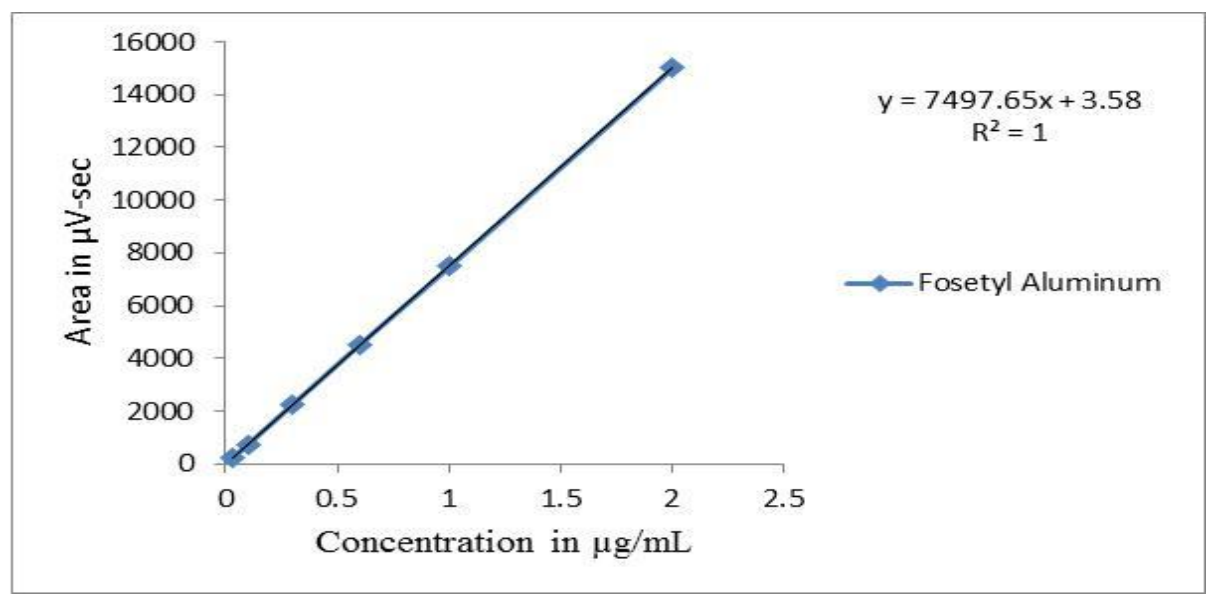




\section{Calculations}

The concentration of acetaminophen in the samples analyzed by HPLC was determined directly from the standard curve.

$\mathrm{Y}=\mathrm{mx}+\mathrm{c}$

Where,

$\mathrm{Y}=$ peak area of standard $\left(\mu \mathrm{V}^{*} \mathrm{sec}\right)$

$\mathrm{m}=$ the slope of the line from the calibration curve

$\mathrm{x}=$ concentration of injected sample $(\mathrm{mg} / \mathrm{L})$

$\mathrm{c}=$ ' $\mathrm{y}$ ' intercept of the calibration curve

The recovered concentration or Dose concentration was calculated by using the formula:

Recovered
$\begin{aligned} & \text { concentration } \\ & \text { concentration }\end{aligned}$

Where,

$\mathrm{m}=$ the slope of the line from the calibration curve

$\mathrm{x}=$ sample area of injected sample $\left(\mu \mathrm{V}^{*} \mathrm{sec}\right)$

$\mathrm{c}=$ ' $\mathrm{y}$ ' intercept of the calibration curve

$\mathrm{D}=$ Dilution Factor

$\mathrm{P}=$ Purity of Test item

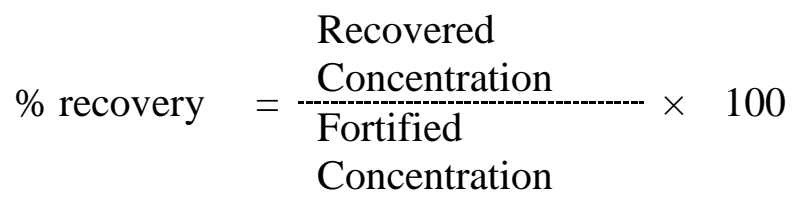

In conclusion, this paper describes a fast, simple sensitive analytical method based on HPLC-PDA to determine the fosetyl aluminum residues in garlic. The LLE extraction procedure is very simple and inexpensive method for determination of fosetyl aluminum residues in garlic. Satisfactory validation parameters such as linearity, recovery, precision and LOQ were established by following South African National Civic Organization (SANCO) guidelines. Therefore, the proposed analytical procedure could be useful for regular monitoring, residue labs and research scholars to determine the fosetyl aluminum residues in different commodities (fruit, juice, seed, oil, and water and soil samples).

\section{Acknowledgement}

The authors are thankful to the Dr. Gowtham Prasad, S.V.V University, Hyderabad for his keen interest and help.

\section{References}

Barrett, S.R., Shearer, B.L., Hardy G.E.S. 2003. The efficacy of phosphite applied air inoculation on the colonisation of Banksia brownii stems by Phytophthora cinnamomi. Australas. Plant Path., 32: $1-7$.

Giordano, R., Ciaralli, L., Ciprotti, M., Camoni, I., Costantini, S.1995. Applicability of high- performance ion chromatography (HPIC) to the determination of fosetyl-aluminum in commercial formulations. Microchem. $J ., 52:$ 68-76.

Hernández, F., Sancho, J.V., Pozo, Ó.J., Villaplana, C., Ibánez, M., Grimalt, S. 2003. Rapid determination of fosetylaluminum residues in lettuce by liquid chromatography/ electrospray tandem mass spectrometry. J. AOAC Int., 86: 832-838.

Hooijschuur, E.W.J., Kientz, C.E., Dijksman, J., Brinkman, U.A.T. 2001. Potential of microcolumn liquid chromatography and capillary electrophoresis with flame photometric detection for determination of polar phosphorus containing pesticides. Chromatographia, 54: 295301. 
Moller, K., Jensen, B., Andersen, H.P., Stryhnz, H., Hocken- hull, J. 2003. Biocontrol of Pythium tracheiphilum in Chinese cabbage by Clonostachys rosea under field conditions. Biocontrol Sci. Techn., 13: 171-182.

Nageswara Rao, T., et al., 2012. Determination of four neonicotinoid insecticide residues in cotton seed oil using matrix solid-phase dispersion coupled to high-performance liquid chromatography with ultraviolet detection. Int. J. Pharmaceutical, Chem. Biol. Sci., 2(4): 447-452.

Ouimette, D.G., Coffey, M.D. 1989. Phosphonate levels in avocado (Persea americana) seedlings and soil following treatment with fosetyl-Al or potassium phosphonate. Plant Dis., 73: 212-215. Pelegri, R., Gamón, M., Coscollá, R., Beltrán, V., and Cunat, P. 1993. The metabolism of fosetyl- aluminum and the evolution of residue levels in oranges and tangerines. Pesticide Sci., 39: 319-323.

SANCO Guidelines. Method validation and quality control procedures for pesticide residues analysis in food and feed. Document No. SANCO/10684/2009.

Tentu Nageswara Rao., et al., 2015. Determination of Ethoxysulfuron Residues in Sugarcane Juice followed by HPLC-PDA Detection and Confirmation of Residues by LCMS/MS. Eurasian J. Anal. Chem., 10(3): 187-194.

\section{How to cite this article:}

Nageswara Rao Tentu, Botsa Parvatamma, Karri Apparao, Prathipati Revathi and Prashanthi, Y. 2017. Determination of Fosetyl Aluminium Fungicide Residues in Garlic using HPLC Method. Int.J.Curr.Microbiol.App.Sci. 6(2): 231-238. doi: http://dx.doi.org/10.20546/ijcmas.2017.602.030 